\title{
ISOLAMENTO DE MYXOVIRUS PARAINFLUENZA 3 DE GADO BOVINO NO ESTADO DE SÃO PAULO, BRASIL
}

Candeias, J. A. N. et al. - Isolamento de myxovirus parainfluenza 3 de gado bovino no Estado de São Paulo, Brasil. Rev. Saúde públ., S. Paulo, 5: 207-12, 1971.

Resumo - Faz-se referência ao isolamento, em São Paulo, de 4 cêpas de Myxovirus parainfluenza do tipo 3, do tecido pulmonar de gado bovino com lesões de pneumonia, que se mostraram antigenicamente semelhantes à cêpa bovina SF-4. Uma das cêpas isoladas mostrou certa relação antigênica com a cêpa humana HA-1.

UNITERMos - Myxovirus parainfluenza 3*; Pneumonia*; Gado bovino*; Cêpa bovina SF-4; Cêpa humana HA-1.

\section{INTRODUCAO}

ReIsinger et al. ${ }^{18}$ isolaram, da secrerão nasal de bovinos com "febre dos transportes", uma cêpa de vírus parainfluenza do tipo 3. Esta observação foi complementada, em têrmos da relação etiológica, pelas pesquisas de Honrlein et al. ${ }^{13}$ e ABINANTI \& HUebner ${ }^{1}$. Trabalhos posteriores ${ }^{2}$, $4,7,11,16,21$ vieram confirmar os resultados destas pesquisas. A relação antigênica entre as cêpas isoladas de bovinos e caprinos e a cêpa humana HA-1 foi estudada por Henle et al. ${ }^{12}$, Abinanti et al. ${ }^{3} \mathrm{e}$ KETLER et al. ${ }^{15}$. No Brasil, os dois primeiros inquéritos sorológicos, em relação ao vírus parainfluenza 3 , feitos em gado bovino leiteiro do Estado de São Paulo ${ }^{5,}$, evidenciaram não só uma elevada porcentagem de animais com anticorpos inibidores da hemaglutinação para as cêpas SF-4 e HA-1, mas permitiram, também, demonstrar a relação antigênica existente entre as cêpas humana e bovina. Apresentamos os resultados da tentativa de isolamento de Myxovirus parainfluenza de gado bovino com quadros pneumônicos.

\section{MATERIAL E METODOS}

Foram utilizadas culturas primárias de rim de macaco rhesus e rim de bovino. As primeiras, obtidas de fonte comercial,

Recebido para publicação em 28-7-1971.

(1) Do Departamento de Microbiologia e Imunologia do Instituto de Ciéncias Biomédicas da USP - Av. Dr. Arnaldo, 715, São Paulo, SP - Brasil.

(2) Da Secção de Toxicologia e Higiene Comparada do Instituto Biológico - Av. Cons. Rodrigues Alves, 1252, Sáo Paulo, SP - Brasil.

(3) Da Secção de Virus do Instituto Biológico - Av. Cons. Rodrigues Alves, 1252, São Paulo, SP - Brasil. 
CANDEIAS, J. A. N. et al. - Isolamento de myxovirus parainfluenza 3 de gado bovino no Estado de São Paulo, Brasil. Rev. Saúde públ., S. Paulo, 5:207-12, 1971.

foram preparadas em meios de Melnick A e B e as segundas em meio de Hanks' contendo $20 \%$ de sôro bovino; o meio de manutenção utilizado nas culturas de rim de bovino e de macaco rhesus foi o meio 199.

Os espécimens para inoculação prepararam-se por trituração dos fragmentos de tecido pulmonar, com lesões pneumônicas, em solução fosfatada tamponada contendo $0,75 \%$ de albumina bovina e 1.000 unidades de penicilina e $1.000 \mathrm{~m} \mu$ de estreptomicina por mililitro, de modo a obter-se uma suspensão final a $10 \%$. Após centrifugação a 500 r.p.m., durante $15 \mathrm{~min}$, utilizou-se o sobrenadante para inoculação das culturas celulares, usando-se 0,2 ml por cultura. A multiplicação viral foi confirmada pelo ECP e pela prova de hemadsorção com hemácias de cobaia ${ }^{23}$. As culturas foram mantidas a $33^{\circ} \mathrm{C}$, em sistema giratório e a $37^{\circ} \mathrm{C}$, em sistema estacionário.

As reações de neutralização e fixação do complemento foram executadas segundo a técnica descrita por KetLER et al. ${ }^{15}$.
Executaram-se reaçōes de neutralização cruzada entre as cêpas isoladas $e$ as cêpas SF-4 e HA-l (1), usando soros padrões anti-SF-4 e anti-HA-1 e soros preparados em coelho. Estes foram obtidos com duas inoculações endovenosas das cêpas bovinas isoladas, com 15 dias de intervalo. A sangria dos animais imunizados foi feita 20 dias após a primeira inoculação.

\section{RESULT A DOS}

Do total de espécimens de tecido pulmonar obtido de 25 bovinos, abatidos em matadouro, com lesões pneumônicas, foram isoladas 4 cêpas de Myxovirus parainfluen$z a$ do tipo 3. Os títulos obtidos em cultura de rim de bovino não ultrapassaram, para qualquer das cêpas isoladas, $10^{\circ, 5}$ DICT $_{50}$ por mililitro. A reação de inibição da hemadsorção feita com soros padróes para Myxovirus parainfluenza dos tipos 1, 2 e 3 levou à caracterização de tôdas as cêpas como pertencendo ao tipo 3 . O tratamento das cêpas bovinas isoladas com $5 \%$ de clo-

T A B E L A 1

Relação antigenica entre as cêpas SF-4 e HA-1 de Myxovirus parainfluenza do tipo 3 e as cêpas bovinas isoladas, evidenciada pela reaçăo de neutralizaçăo.

\begin{tabular}{|c|c|c|c|c|c|c|}
\hline \multirow{2}{*}{$\begin{array}{l}\text { Soros neu- } \\
\text { trallzantes }\end{array}$} & \multicolumn{6}{|c|}{ Reciproca dos títulos de neutralizaçăo } \\
\hline & Cêpa B-2 & Cêpa B-7 & Cepa B-16 & Cêpa B-23 & Cépa SF-4 & Cepa HA-1 \\
\hline $\mathbf{B}-\mathbf{2}$ & 256 & 32 & 128 & 64 & 128 & 16 \\
\hline$B-7$ & 64 & 128 & 64 & 64 & 32 & 64 \\
\hline$B-16$ & 128 & 16 & 128 & 64 & 128 & 16 \\
\hline$B-23$ & 64 & 16 & 64 & 128 & 64 & 8 \\
\hline$S F-4$ & 64 & 32 & 64 & 32 & 128 & 64 \\
\hline $\mathbf{H A}-1$ & 16 & 128 & 16 & 16 & 32 & 256 \\
\hline
\end{tabular}

(1) Cêpas SF-4 e HA-1, cedidas pelo Virus Reference Laboratory - Central Public Health Laboratories - Londres. 
CANDEIAS, J. A. N. et al. - Isolamento de myxovirus parainfluenza 3 de gado bovino no Estado de São Paulo, Brasil. Rev. Saúde públ., S. Paulo, 5:207-12, 1971.

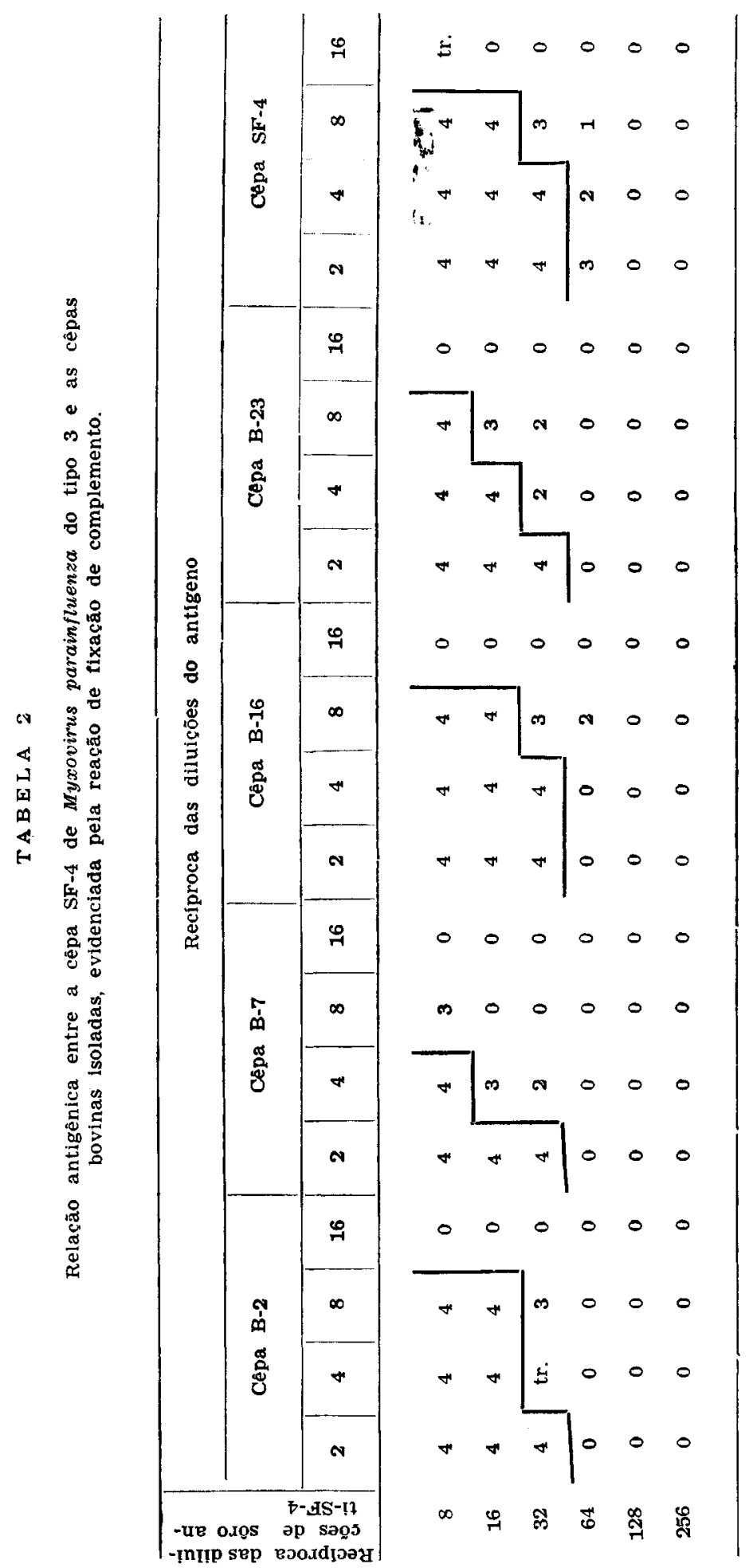


CANDEIAS, J. A. N. et al. -Isolamento de myxovirus parainfluenza 3 de gado bovino no Estado de São Paulo, Brasil. Rev. Saúde puibl., S. Paulo, 5:207-12, 1971.

rofórmio, durante $10 \mathrm{~min}$, resultou na destruição total do poder infetante do vírus. $\mathrm{Na}$ Tabela 1 apresentamos os resultados das reações de neutralização cruzada. Cada vírus isolado foi neutralizado em título mais elevado pelo sôro homólogo. Os títulos de neutralizaçáo obtidos usando os soros preparados contra as cêpas bovinas isoladas e a cêpa SF-4 são elevados e semelhantes, excetuando os relativos à cêpa bovina B-7 e à cêpa humana HA-l. Em relação à cêpa HA-1 obtiveram-se, em geral, títulos de neutralização mais baixos.

$\mathrm{Na}$ Tabela 2 figuram os resultados da reação de fixação de complemento usando o sôro anti-SF-4 e, como antígenos, as diferentes cêpas isoladas. A "titulação em bloco" evidencia que o sôro anti-SF-4 reage igualmente bem com três das cêpas isola. das; há um comportamento diferente em relação à cêpa B-7. Na Tabela 3 apresentamos os resultados da "titulação em bloco" da cêpa B-7 frente ao sôro anti-HA-1.

\section{ISCUSSAO}

Os quadros de pneumonia em gado bovino estão, frequientemente, relacionados com adenovirus ${ }^{8,9}$ e vírus parainfluenza $3^{2,4,18,21} \cdot$ CoLE $^{8}$ refere-se igualmente à participação de reovírus dos tipos 1,2 e 3 e ao estudar a incidência de anticorpos virais para o vírus parainfluenza 3 , em casos de pneumonia de bovinos, encontrou $51 \%$ de casos positivos. As porcentagens por nós encontradas ${ }^{6}$ foram bem mais elevadas, atingindo valores de $84,1 \%$. Porcentagem semelhante foi encontrada por ST. George ${ }^{19}$ na Austrália e na Nova Guiné. 0 vírus parainfluenza 3 parece ser um agente etiológico freqüentemente comprometido em quadros pneumônicos de bovinos.

As quatro cêpas de Myxovirus parain fluenza do tipo 3, isoladas no grupo estudado de 25 animais com lesões pneumônicas, mostraram-se antigênicamente muito semelhantes, talvez idênticas, à cêpa

TABELA 3

Relação antigênica entre as cépas HA-1 e B-7 de Myxovirus parainfluenza do tipo 3 , evidenciada pela reação de fixação de complemento.

\begin{tabular}{|c|c|c|c|c|c|c|c|c|c|}
\hline \multirow{3}{*}{$\begin{array}{l}\text { Recfproca das } \\
\text { diluições de } \\
\text { sôro anti-HA-1 }\end{array}$} & \multicolumn{9}{|c|}{ Reciproca das diluições do antigeno } \\
\hline & \multicolumn{4}{|c|}{ Cêpa B-7 } & \multicolumn{5}{|c|}{ Cêpa HA-1 } \\
\hline & 2 & 4 & 8 & 16 & 2 & 4 & 8 & 16 & 32 \\
\hline 8 & 4 & 4 & 4 & 4 & 4 & 4 & 4 & 4 & 4 \\
\hline 16 & 4 & 4 & 4 & 3 & 4 & 4 & 4 & 4 & $\mathbf{3}$ \\
\hline 32 & 4 & 4 & 4 & 2 & 4 & 4 & 4 & 4 & 2 \\
\hline 64 & 4 & 4 & 4 & 0 & 4 & 4 & 4 & 4 & 0 \\
\hline 128 & 0 & 3 & 2 & 0 & 4 & 2 & 4 & 2 & 0 \\
\hline 256 & 0 & 0 & 0 & 0 & 0 & 1 & 2 & 0 & 0 \\
\hline
\end{tabular}


CANDEIAS, J. A. N. et al. - Isolamento de myxovirus parainfluenza 3 de gado bovino no Estado de São Paulo, Brasil. Rev. Saúde públ., S. Paulo, 5:207-12, 1971.

SF-4; a cêpa bovina B-7 apresentou-se antigênicamente mais próxima da cêpa humana HA-1, muito embora seja semelhante às cêpas bovinas ('Tabelas 1 e 2). A "titulação em bloco", por fixação de complemento, frente ao sôro anti-HA-1 (Tabela 3) também evidenciou uma certa semelhança antigênica entre a cêpa- B-7 e a cêpa humana, o que permite considerar que, das quatro cêpas bovinas isoladas, a cêpa B-7 é a única que parece possuir um componente antigênico comum à cêpa humana HA-1. Nossos resultados com os soros preparados em coelho, com as cêpas bovinas, e o sôro padrão anti-HA-1 (Tabela 1) indicam uma semelhança antigênica nos dois sentidos, frente à cêpa $\mathrm{HA}-1$; as pequenas diferenças observadas podem corresponder a variações antigênicas ocorridas dentro da mesma espécie, podem refletir infecções cruzadas entre espécies diferentes ou podem, simplesmente, ser de natureza casual. Seria necessário estudar um número muito mais amplo de soros para determinar qual o verdadeiro significado das diferenças notadas. A ocorrência de transmissão inter-espécies de vírus parainfluenza 3 tem sido sugerida por vários autores ${ }^{10,11,20,21} \mathrm{e}$ recentemente PRAvI et al. ${ }^{17}$ isolaram de morcêgos frugívoros um nôvo sub-tipo de vírus parainfluenza do tipo 2, demonstrando a presença, em soros humanos, de anticorpos contra êste vírus. É possível que as reações sorológicas do tipo das encontradas entre a cêpa bovina B-7 e a cêpa humana HA-1 sejam simplesmente de natureza heterotípica cruzada, ou o resultado manifesto de recombinações genéticas entre diferentes cêpas de vírus parainfluenza de várias espécies animais, tal como sucede com os sub-tipos de vírus da influenza $A$ isolados do homem e outros animais ${ }^{22}$. Não devemos, por outro lado, esquecer que o processo de maturação dos vírus parainfluenza torna possível a incorporação ao envólucro viral de materiais celulares, cuja presença poderia igualmente ser responsável pelas reaçōes sorológicas cruzadas ${ }^{14}$.
CandeIas, J. A. N. et al. - [Isolation of Myxovirus parainfluenza type 3 from cattle in S. Paulo State, Brazil]. Rev. Saúde puibl., S. Paulo, 5:207-12, 1971.

SUMMARY - The isolation of Myxovirus parainfluenza type 3 from cattle with pneumonia, in S. Paulo, Brazil, is reported. All the strains isolated appeared to be antigenically related to the bovine strain $S F-4$. It was possible to establish a certain degree of antigenic relationship between the human strain HA-1 and one of the bovine strains isolated.

UNITERMS - Myxovirus parainfluenza $3 *$; Cattle pneumonia*; Bovine strain SF-4; Human strain HA-1.

\section{REFERENCIAS BIBLIOGRAFICAS}

1. ABINANTI, F. R. \& HUEBNER, R. J. The serological relationship of strains of parainfluenza 3 virus isolated from humans and cattle with respiratory disease. Virology, 8:391-4, 1959.

2. ABINANTI, F. R. et al. - Observations of infections of cattle with Myxovirus parainfluenza 3. Amer. J. Hyg., 71:52-8, 1960.

3. ABINANTI, F. R. et al. - Relationship of human and bovine strains of Myxovirus parainfluenza 3. Proc. Soc. exp. Biol., New York, 106:466-9, 1960.

4. ABINANTI, F. $R$. et al. - Serologic studies of Myxovirus parainfluenza 3 in cattle and prevalence of antibodies in bovine. J. Immunol., 86:505-11, 1961.

5. CaNNDEIAS, J. A. N. \& RIBEIRO, L. C. - Anticorpos inibidores da hemagiutinacão para o virus parainfluenza 3 (HA-1), em gado bovino. Rev. Saúde públ., S. Paulo, 2:180-5, 1968.

6. CANDEIAS, J. A. N. \& RIBEIRO, L. C. Anticorpos inibidores de hemaglutinação para as cêpas SF-4 e HA-1 de Myxovirus parainfluenza 3 em gado bovino do Estado de São Paulo. Arq. Inst. biol. 37: 129-35, 1970.

7. CHERBY, J. et al. - Serological survey on cattle in France: hemagglutination- 
CANDEIAS, J. A. N. et al. - Isolamento de myxovirus parainfluenza 3 de gado bovino no Estado de São Paulo, Brasil. Rev. Saúde públ., S. Paulo, 5:207-12, 1971.

inhibiting antibodies due to Myxovirus parainfluenza 3. Rec. Méd. vet., 143: 755-65, 1967 apud Vet. Bull., 38:310, 1968.

8. COLE, A. M. - The aetiology of calf pneumonia in Queensland. Aust. vet. $J .$, 46:576-80, 1970 .

9. COLE, A. M. - The isolation of adenovirus from calves with pneumonia. Aust. vet. J., 46:569-75, 1970 .

10. FISCHMAN, H. R. - Epidemiology of parainfluenza 3 infection in sheep. Amer. J. Epidem., 85:272-81, 1967.

11. FISCHMAN, H. R. - Presence of neutralizing antibody for Myxovirus parainfluenza 3 in sheep sera. Proc. Soc. exp. Biol., New York, 118:725-7, 1965.

12. HENLE, G. et al. - The serologic relationship of strains of Parainfluenza 3 virus isolated from humans and cattle with respiratory disease. Virology, 8:391-3, 1959.

13. HOERLEIN, A. B. et al. - Studies of shipping fever of cattle. I. Parainfluenza 3 virus antibodies in feeder calves. $J$. Amer. vet. med. Ass., $135: 153-60,1959$.

14. HOLLINGER, F. B. \& PRAVI, K. M. Bat parainfluenza virus. Immunological, chemical and physical properties. Amer. J. trop. Med. Hyg., 20:131-8, 1971.

15. KETLER, A. et al. - Laboratory and field investigations of bovine Myxovirus parainfluenza 3 virus and vaccine. $\mathrm{I}$. Properties of the SF-4 (shipping fever) strain of virus. J. Immunol., 87:126-33, 1961.
16. KRAMER, L. L. et al. - Epizootiology of bovine Myxovirus parainfluenza 3 (SF-4) in Nebraska cattle as determined by antibody titers. J. Amer. vet. med. Ass., $142: 375-8,1963$.

17. PRAVI, K. M. et al. - Isolation of a new parainfluenza virus from a frugivorous bat, Rousettus leschenaulti, collected at Poona, India. Amer. J. trop. Med. Hyg., 20:125-30, 1971

18. REISINGER, R. C. et al. - A Myxovirus (SF-4) associated with shipping fever of cattle. J. Amer vet. med. Ass., 135:147$52,1959$.

19. ST. GEORGE, T. D. - A bovine strain of Myxovirus parainfluenza type 3 - Experimental transmission and a survey of antibodies in cattle in Australia and New Guinea. Aust. vet. J., 45:315-20, 1969.

20. ST. GEORGE, T. D. - The isolation of Myxovirus parainfluenza type 3 from sheep in Australia. Aust. vet. J. 45:321-5, 1969.

21. ST. GEORGE, T. D. \& FRENCH, E. L. - Isolation of a bovine strain of Myxovirus parainfluenza type 3 in Australla. Aust. vet. J., 42:438-9, 1966.

22. TUMOVA, B. \& PEREIRA, H. G. Genetic interaction between influenza $A$ viruses of human and animal origin. Virology, 27:253-61, 1965.

23. VOGEL, J. \& SHELOKOV, A. - Adsorption - hemagglutination test for influenza virus in monkey Kidney tissue culture. Science, $126: 358-59,1957$. 